Article

\title{
Activation of Persulfate by Biochars from Valorized Olive Stones for the Degradation of Sulfamethoxazole
}

\author{
Elena Magioglou ${ }^{1}$, Zacharias Frontistis ${ }^{2}{ }^{\mathbb{D}}$, John Vakros ${ }^{1,3}$, Ioannis D. Manariotis ${ }^{4}$ and \\ Dionissios Mantzavinos 1,3,*(D) \\ 1 Department of Chemical Engineering, University of Patras, Caratheodory 1, University Campus, \\ GR-26504 Patras, Greece; mag.elena14@hotmail.gr (E.M.); vakros@chemistry.upatras.gr (J.V.) \\ 2 Department of Environmental Engineering, University of Western Macedonia, GR-50100 Kozani, Greece; \\ zaxoys@gmail.com \\ 3 INVALOR: Research Infrastructure for Waste Valorization and Sustainable Management, Caratheodory 1, \\ University Campus, GR-26504 Patras, Greece \\ 4 Department of Civil Engineering, Environmental Engineering Laboratory, University of Patras, \\ University Campus, GR-26504 Patras, Greece; idman@upatras.gr \\ * Correspondence: mantzavinos@chemeng.upatras.gr; Tel.: +30-26-1099-6136
}

Received: 9 April 2019; Accepted: 24 April 2019; Published: 3 May 2019

\begin{abstract}
Biochars from spent olive stones were tested for the degradation of sulfamethoxazole (SMX) in water matrices. Batch degradation experiments were performed using sodium persulfate (SPS) as the source of radicals in the range $250-1500 \mathrm{mg} / \mathrm{L}$, with biochar as the SPS activator in the range 100-300 mg/L and SMX as the model micro-pollutant in the range 250-2000 $\mu \mathrm{g} / \mathrm{L}$. Ultrapure water (UPW), bottled water (BW), and secondary treated wastewater (WW) were employed as the water matrix. Removal of SMX by adsorption only was moderate and favored at acidic conditions, while SPS alone did not practically oxidize SMX. At these conditions, biochar was capable of activating SPS and, consequently, of degrading SMX, with the pseudo-first order rate increasing with increasing biochar and oxidant concentration and decreasing SMX concentration. Experiments in BW or UPW spiked with various anions showed little or no effect on degradation. Similar experiments in WW resulted in a rate reduction of about $30 \%$, and this was attributed to the competitive consumption of reactive radicals by non-target water constituents. Experiments with methanol and $t$-butanol at excessive concentrations resulted in partial but generally not complete inhibition of degradation; this indicates that, besides the liquid bulk, reactions may also occur close to or on the biochar surface.
\end{abstract}

Keywords: adsorption; antibiotics; emerging micro-pollutants; waste valorization; water matrix

\section{Introduction}

Over the past decades, the occurrence of harmful xenobiotic compounds in the environment has constantly been increasing. This causes a number of serious problems related to human health, the quality of surface- and groundwaters, and generally, ecosystem protection. Thus, much work has been performed for the remediation of sites contaminated by persistent pollutants [1,2].

Amongst different classes of pollutants, pharmaceuticals and especially antibiotics have attracted the interest of the scientific community due to adverse effects associated with their existence in water bodies [3]. In particular, many scientists alarmingly state that exposure to antibiotics can lead to increased antimicrobial resistance [4]. It is, therefore, not surprising that a large number of studies deal with the removal of common antibiotics, such as sulfamethoxazole (SMX) and amoxicillin, with different physicochemical processes, such as photocatalysis [5], ozonation [6], Fenton-like reaction [7], electrochemical oxidation [8], and sonochemistry [9]. 
In recent years, the use of persulfates as a source of the sulfate radical, $\mathrm{SO}_{4} \bullet^{-}$, has become attractive for in situ oxidation, since it is more stable, easy to store, and less costly than other oxidants such as hydrogen peroxide [10]. The conversion of persulfates to sulfate radicals requires some kind of activation agent, including transition metals, high temperatures, UV irradiation, ultrasound irradiation, and microwaves, amongst others [11-15]. Of these, heterogeneous catalysis exhibits several advantages such as easy recovery of the catalysts and possible reuse, relatively low concentrations, and higher efficiency $[14,15]$. In recent years, there have been several reports concerning the use of carbonaqueous materials such as graphene, graphene oxide, carbon nanotubes, and activated carbons as persulfate activators [16-19].

Biochars, the solid residue produced from biomass thermal decomposition with no or little oxygen at moderate temperatures, are low-cost materials with high surface area and desirable physicochemical properties in terms of pore size distribution, the amount of functional groups (e.g., $\mathrm{C}-\mathrm{O}, \mathrm{C}=\mathrm{O},-\mathrm{COOH}$, $-\mathrm{OH}$ ), and minerals (e.g., $\mathrm{N}, \mathrm{P}, \mathrm{S}, \mathrm{Ca}, \mathrm{Mg}$, and $\mathrm{K}$ ) that can be employed as adsorbents, catalysts or catalytic supports [20-24]. Moreover, they can be employed for carbon storage, thus avoiding the emission of 0.1-0.3 billion tons of $\mathrm{CO}_{2}$ annually [25]. Although any kind of lignocellulosic biomass can be used for biochar production, its origin may have a significant effect on properties, such as the moisture content and the composition in terms of organic carbon, minerals, and ash content. Furthermore, the pyrolysis temperature can influence the surface area and the point of zero charge, pzc, of the produced biochars [26,27].

The ability of biochars to activate persulfates has been demonstrated in a few recent studies [28-30]. The use of a metal-free material originating from valorized biomass is a rather attractive concept since conventional catalysts can be replaced by a green material [28,29].

In a recent study of our group [30], we demonstrated the use of biochar from spent malt rootlets for persulfate activation and the subsequent oxidation of the antibiotic SMX. Effective persulfate activation took place on the biochar surface followed by considerable degradation of SMX in various environmental matrices, such as bottled water and secondary treated wastewater.

In this work, biochar from olive stones was prepared, exhaustively characterized, and eventually tested for the adsorption and oxidative degradation of SMX by means of activated persulfate.

\section{Results and Discussion}

\subsection{Biochar Properties}

The thermogravimetric analysis (TGA) curve of the prepared biochar is shown in Figure 1. As can be seen, there is a significant mass loss of about $10 \%$ starting at about $100{ }^{\circ} \mathrm{C}$. This is due to water and moisture content that has been adsorbed in the biochar. Between 450 and $600{ }^{\circ} \mathrm{C}$, the biochar is almost completely burned, while only a small amount (ca. $7 \%$ ) corresponding to minerals remains. The carbonaqueous phase is almost homogeneous, as can be seen from the differential curve of the TGA results.

Figure 2 presents the titration curves for a blank solution and the biochar suspension. The point of zero charge coincides with the section point between these two curves, which is at around 3 . The rather expected acidic character of the biochar has to do with the increased oxygen content of the starting biomass and the limited $\mathrm{O}_{2}$ atmosphere in the pyrolysis step. Oxygen helps the formation of surface groups with acidic behavior, while the presence of minerals at low concentrations (see Figure 1) is also consistent with the reduced sample basicity. Interestingly, the biochar surface does not exchange significant amounts of $\mathrm{H}^{+}$at $\mathrm{pH}>3$, as can be seen from the titration curve in the $10>\mathrm{pH}>4$ region, as well as in the inset of Figure 2. The inset of Figure 2 represents the amount of $\mathrm{H}^{+}$consumed by the surface groups. As a result, the total negative charge of the surface is not expected to be high at $\mathrm{pH}>3$.

The specific surface area (SSA) of the sample was measured equal to $50 \mathrm{~m}^{2} / \mathrm{g}$ using the BET equation. The microporous surface area, calculated with the $t$-plot method, was found equal to $44 \mathrm{~m}^{2} / \mathrm{g}$. The pore size distribution is presented in Figure 3. The microporous has a diameter of $2 \mathrm{~nm}$, 
while there are some mesoporous-macroporous with an average diameter greater than $160 \mathrm{~nm}$. Almost no mesoporous was observed in the range of $5-100 \mathrm{~nm}$.

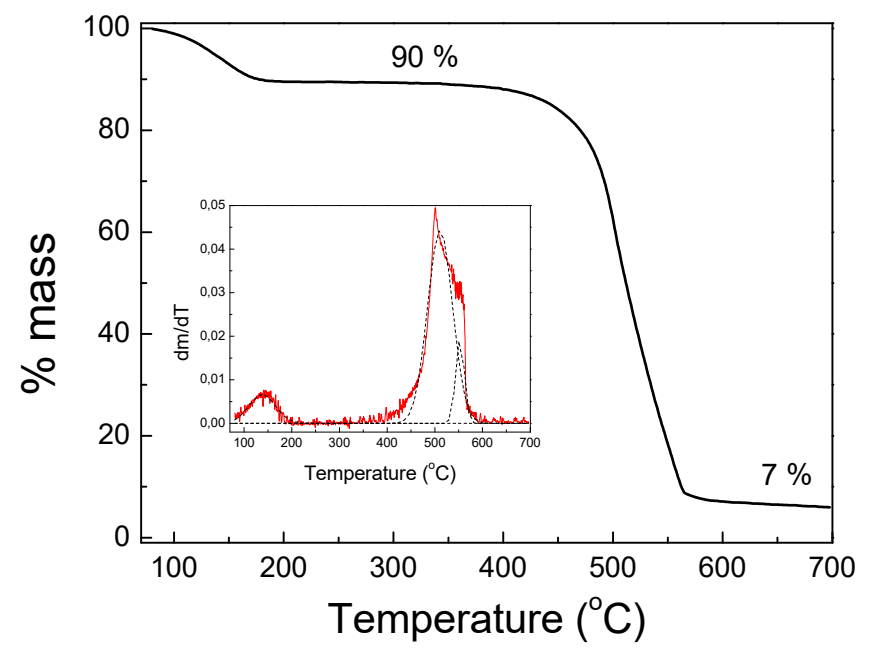

Figure 1. TGA curve obtained at a heating rate of $10^{\circ} \mathrm{C} / \mathrm{min}$ under $20 \mathrm{~mL} / \mathrm{min}$ air flow. Inset: Differential TGA graph.

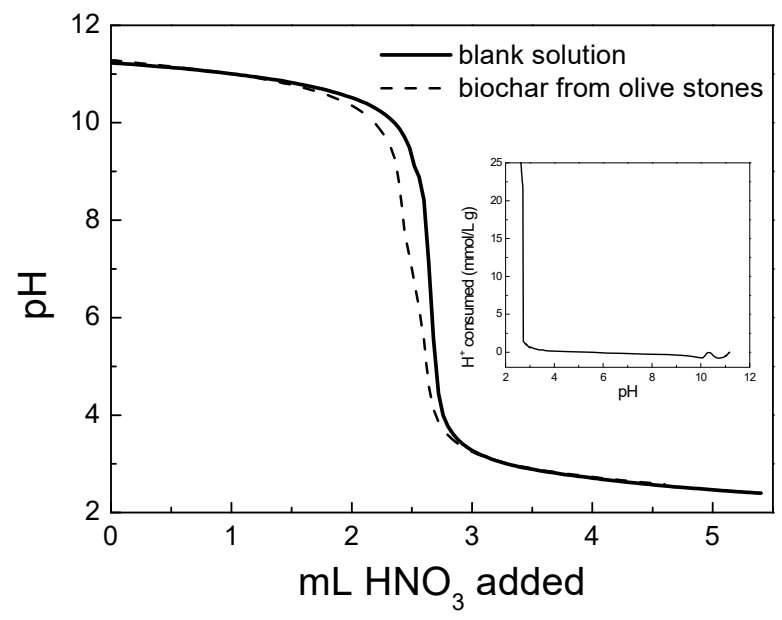

Figure 2. PMT curves for the blank solution (solid line) and the biochar suspension (dotted line). Inset: Consumption of $\mathrm{H}^{+}$ions by the surface as a function of suspension $\mathrm{pH}$.

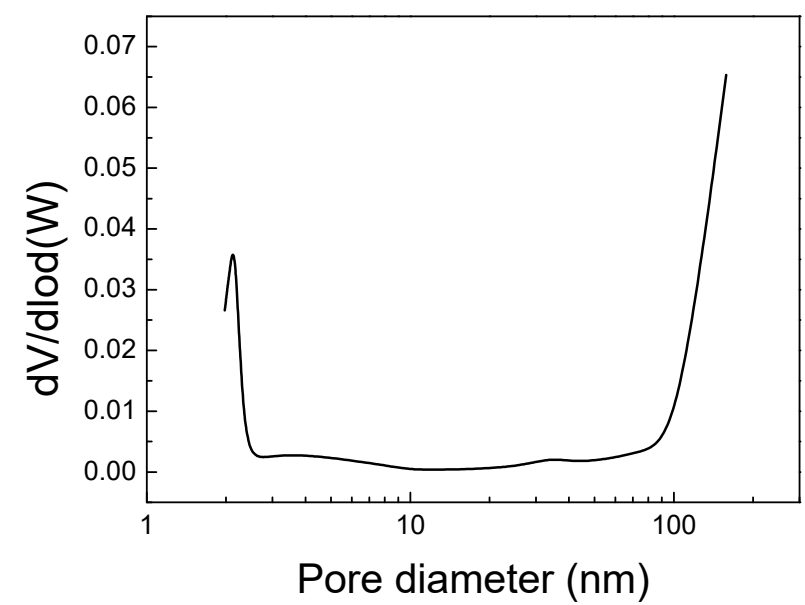

Figure 3. Pore size distribution of the biochar. 
Representative SEM images in Figure 4a,b shows that the surface is covered with deposits. Due to the moderate SSA and the absence of mesoporosity, the content of these deposits is not expected to be significant since it is limited to the external surface area in accordance with the TGA results. EDS analysis (Figure $4 \mathrm{c}$ ) shows that $\mathrm{C}$ and $\mathrm{O}$, respectively, comprise almost $90 \%$ and $6 \%$ in atomic ratio, while the two elements account for almost $90 \%$ of the total mass. Other elements detected are $\mathrm{K}, \mathrm{Ca}$, $\mathrm{Na}, \mathrm{Mg}$, Si, and $\mathrm{Cl}$, with $\mathrm{Cl}(1.53 \%$ atomic ratio), $\mathrm{Na}$ ( $0.9 \%$ atomic ratio), and $\mathrm{K}(0.6 \%$ atomic ratio) existing in higher amounts.

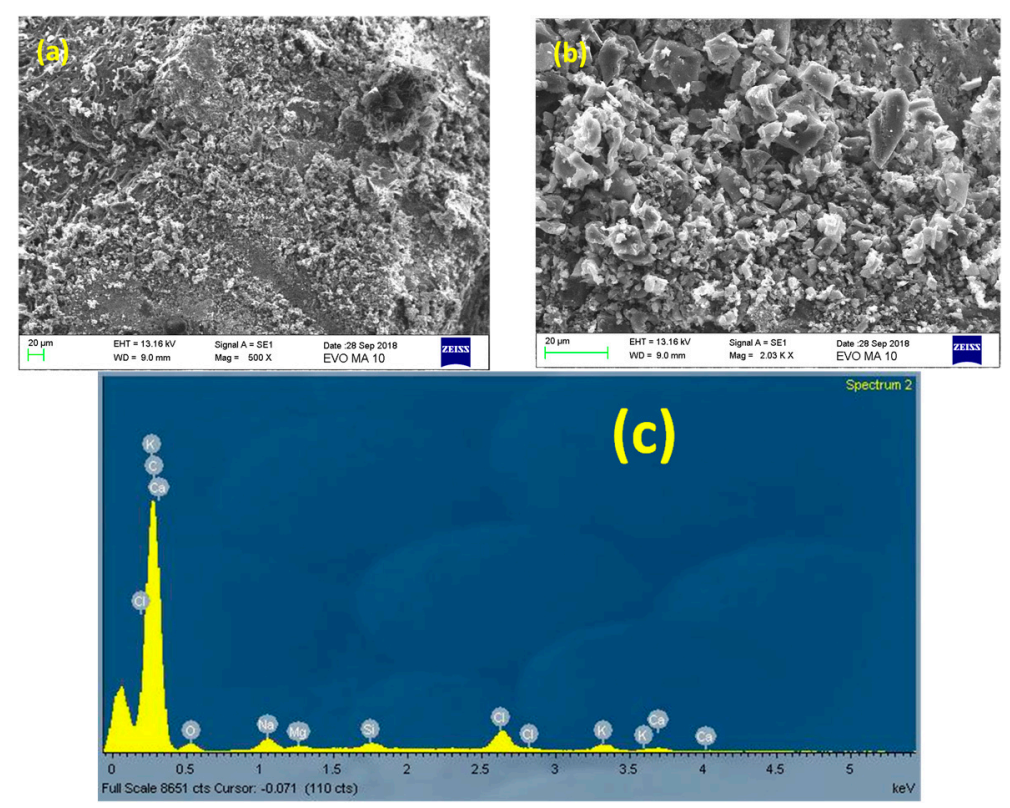

Figure 4. SEM images (a) and (b) and EDS analysis (c) of the biochar.

The FTIR spectrum of the biochar (Figure 5) exhibits a wide band at $3436 \mathrm{~cm}^{-1}$ and a peak at $1045 \mathrm{~cm}^{-1}$ mainly due to $\mathrm{H}_{2} \mathrm{O}$ content, in accordance with TGA results and surface $\mathrm{C}-\mathrm{OH}$ groups. The aromatic character is not significant as evidenced by the absence of peaks above $3000 \mathrm{~cm}^{-1}$ ( $\mathrm{C}-\mathrm{H}$ in aromatic compounds). The low intensity of the peaks in the region $1000-1800 \mathrm{~cm}^{-1}$ is characteristic of the heterogeneity of the biochar. The peak at $1580 \mathrm{~cm}^{-1}$ can be attributed to $C=C$ with conjugation of $\pi$ electrons [31] by functional groups with high electronegativity. Finally, the peak at $1742 \mathrm{~cm}^{-1}$ can be assigned to $\mathrm{C}=\mathrm{O}$ groups, while the peaks at 2922 and $2846 \mathrm{~cm}^{-1}$ are due to $\mathrm{C}-\mathrm{H}$ bonds [32,33].

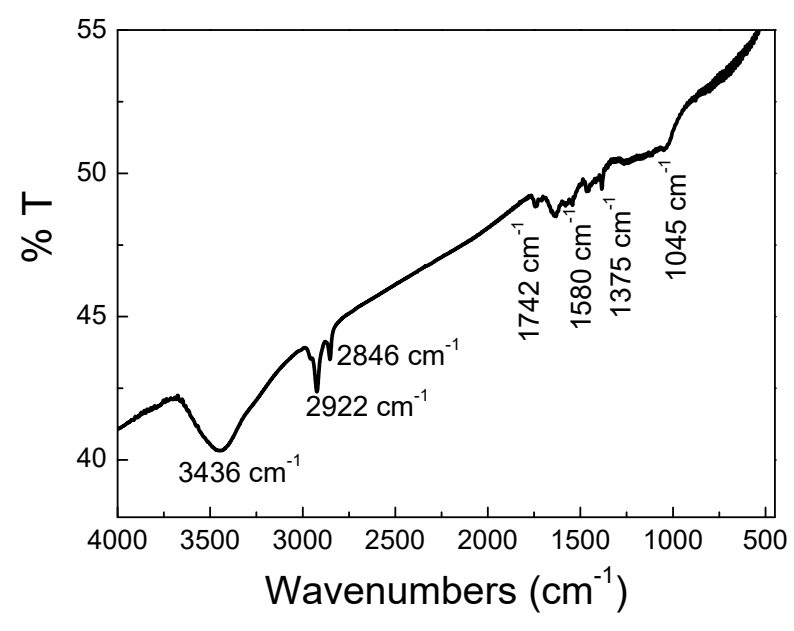

Figure 5. The FTIR spectrum of the biochar. 
The XRD pattern of the biochar (Figure 6) clearly shows the amorphous carbon phase with a wide peak at $25^{\circ}$. This peak is typical of a carbonaceous material with a less ordered structure due to pyrolysis. The intense sharp peaks are identified as halite, and this is supported by the EDS analysis shown in Figure 4c.

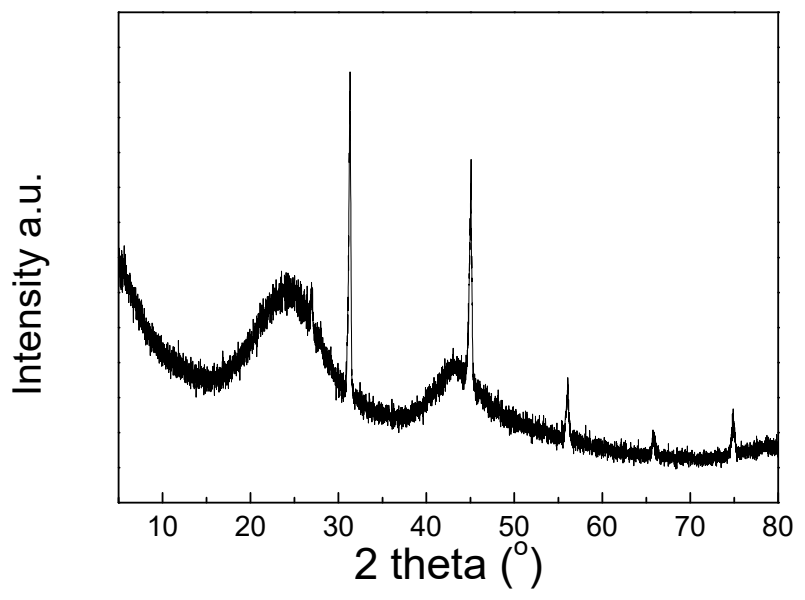

Figure 6. The XRD pattern of the biochar.

\subsection{Adsorption Capacity}

The adsorption isotherm of SMX at $\mathrm{pH}=6.5$ and ambient temperature is shown in Figure 7.

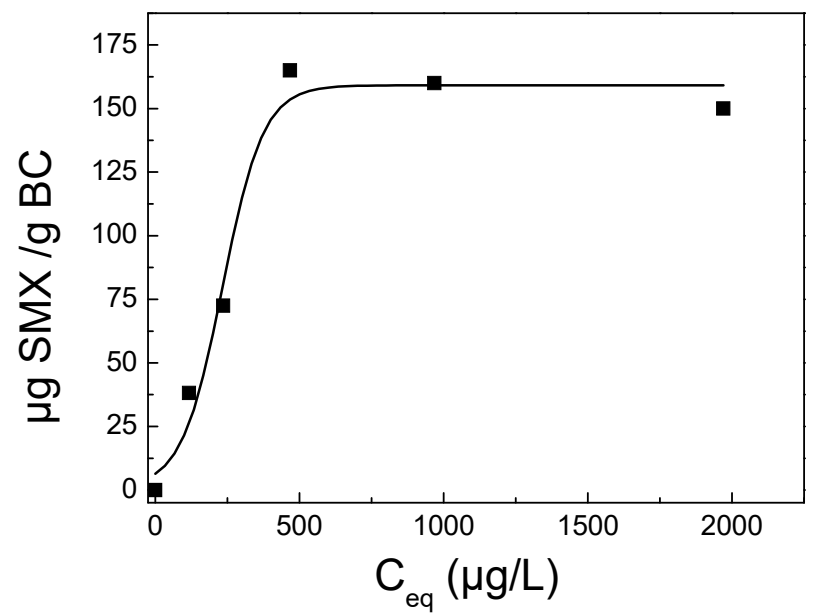

Figure 7. Adsorption isotherm of sulfamethoxazole (SMX) at $\mathrm{pH}=6.5$, ambient temperature, and $200 \mathrm{mg} / \mathrm{L}$ biochar.

As can be seen, SMX concentrations up to $500 \mu \mathrm{g} / \mathrm{L}$ can saturate the surface with the adsorption maximum being about $150 \mu \mathrm{g} / \mathrm{g}$ of the biochar (BC). The amount of adsorbed SMX on biochar in the range $100-300 \mathrm{mg} / \mathrm{L}$ is almost constant and equal to $8 \%$, leaving more than $90 \%$ of SMX in the solution (data not shown). The starting solution $\mathrm{pH}$ was 5.8 and slightly increased after sorption to 6.5-7. This $\mathrm{pH}$ shift is typical of an anion sorption behavior, implying that the adsorption of SMX is closely related to the negative charge of SMX. The $\mathrm{p} K_{a}$ value of the sulfonamide group of SMX is about 5.7 and the isoelectric point 4.5. Generally, at $\mathrm{pH}$ values $<1.4, \mathrm{SMX}$ exists as a cation with the terminal $-\mathrm{NH}_{2}$ group being protonated, while at a $\mathrm{pH}>5.8$, $\mathrm{SMX}$ is negatively charged with deprotonation of $-\mathrm{NH}$ in the sulfonoamido group. On the other hand, SMX is characterized by a low positive charge and can be considered as neutral at $1.4<\mathrm{pH}<5.8[34,35]$.

Briefly, when an anion concentration increases in the interfacial region, the surface releases $\mathrm{OH}^{-}$ into the solution to partially neutralize the negative charge of the surface. The increment of $\mathrm{pH}$ results 
in a more negatively charged surface as well as more negatively charged SMX species and thus a lower deposition of SMX onto the biochar surface. Even if SMX interacts with the $\mathrm{C}=\mathrm{C}$ bonds, as has been reported in the literature [36], the negative charge increases and should be partially neutralized.

The influence of the solution $\mathrm{pH}$ on the adsorption is significant. As can be seen in Figure 8, the deposition of SMX is rather low at high $\mathrm{pH}$ (i.e., final $\mathrm{pH}>7$ ), while it is significant at low $\mathrm{pH}$ in accordance with the literature [37,38]. Since the pzc of the biochar is 3 and the isoelectric point of SMX 4.5, both the surface and SMX are negatively charged at high $\mathrm{pH}$ values, so adsorption is not favored. Two experiments were performed at an initial $\mathrm{pH}$ value of 5.7: one was buffered at this value, while the other was left uncontrolled reaching a final value of 7.2. In the latter case, SMX adsorption is evidently slower than in the former, thus pointing out the significance of $\mathrm{pH}$. Fast adsorption occurs at $\mathrm{pH}=3$, where the biochar has almost zero charge and has the ability to consume a significant amount of $\mathrm{H}^{+}$ions without altering the solution $\mathrm{pH}$, while $\mathrm{SMX}$ is slightly positively charged and therefore can approach the surface and become adsorbed. The ability of biochar to consume $\mathrm{H}^{+}$in this $\mathrm{pH}$ region helps the sorption process, which can be either electrostatic, due to the different charged surface sites and SMX molecules, or due to the reaction of SMX with the surface-OH groups.

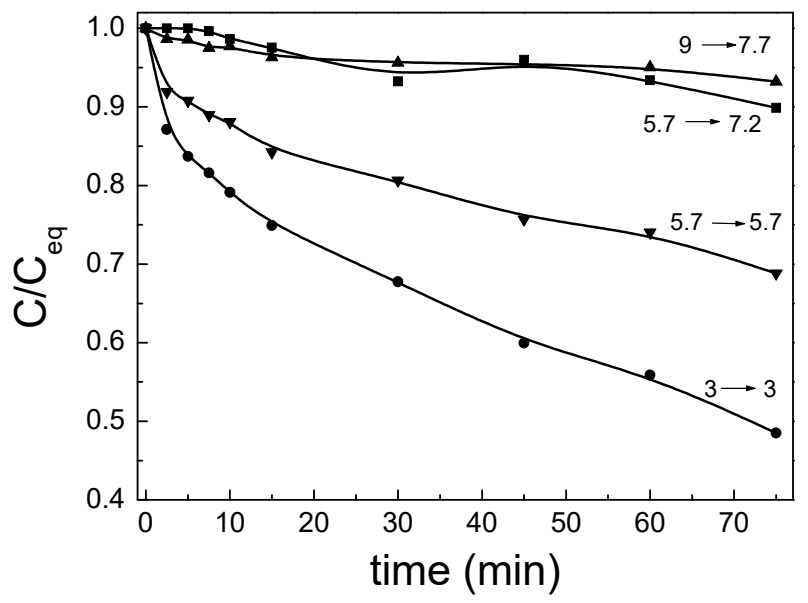

Figure 8. Kinetics of $500 \mu \mathrm{g} / \mathrm{L} \mathrm{SMX}$ adsorption as a function of solution $\mathrm{pH}$ with $200 \mathrm{mg} / \mathrm{L}$ biochar. For each experiment, the starting and final $\mathrm{pH}$ values are indicated.

On the other hand, the biochar surface exhibits small differences at $4<\mathrm{pH}<10$, showing a small degree of $\mathrm{H}^{+}$consumption. At higher than pzc, the surface is charged negatively releasing $\mathrm{H}^{+}$in the solution and thus lowering the solution $\mathrm{pH}$ and making SMX less negative, both of which help the deposition of SMX onto the biochar surface. At $\mathrm{pH}=5.7$, the total negative surface charge of biochar is less than it is at $\mathrm{pH}=9$, and the SMX is also less negative. Therefore, it is easier for SMX to approach the surface and become sorbed. In the $4<\mathrm{pH}<10$ region, deposition is not electrostatic but probably involves surface reactions between surface groups and SMX or hydrogen bonding due to high -O content of the biochar. As pH increases, SMX deposition becomes more difficult, and equilibrium is reached more slowly. This explains why the adsorption/deposition of SMX onto the biochar surface is almost the same at $\mathrm{pH} 7-7.7$ regardless of the starting $\mathrm{pH}$. In a buffer system, there are no changes in $\mathrm{pH}$, while the speciation of SMX and the surface of biochar are not altered during deposition. The $\mathrm{pH}$ value remains low and the deposition is higher, as can be seen in Figure 8.

\subsection{Oxidative Degradation of SMX}

\subsubsection{Effect of Biochar, Sodium Persulfate, and SMX Concentration}

Figure 9 shows the effect of biochar concentration on SMX degradation in the presence of sodium persulfate (SPS). The concentration profiles are normalized against the equilibrium concentration of $\mathrm{SMX}, \mathrm{C}_{\mathrm{eq}}$, after adsorption for $15 \mathrm{~min}$. 


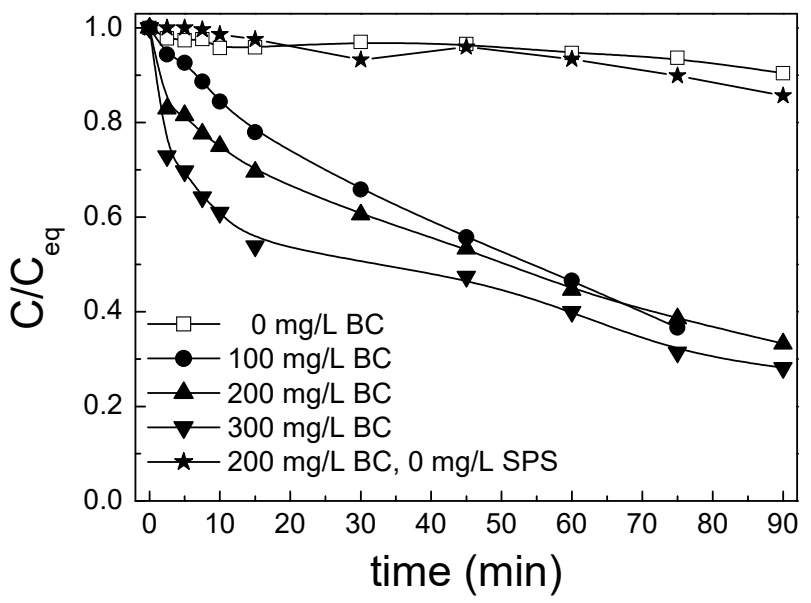

Figure 9. Effect of biochar concentration on $500 \mu \mathrm{g} / \mathrm{L} \mathrm{SMX} \mathrm{degradation} \mathrm{with} 1000 \mathrm{mg} / \mathrm{L}$ sodium persulfate (SPS) in ultrapure water (UPW) and inherent $\mathrm{pH}$.

Persulfate alone, although a mild oxidant itself, is not capable of degrading SMX to an appreciable extent, leading to ca. $10 \%$ removal after 75 min of reaction. Similarly, the extent of adsorption onto $300 \mathrm{mg} / \mathrm{L}$ biochar without oxidant is not considerable, and this is consistent with the adsorption data shown in Figure 8 for experiments at neutral conditions (i.e., the $\mathrm{pH}$ changed from 5.7 to 7.3 during the adsorption experiment shown in Figure 9). The simultaneous use of biochar and oxidant is evidently beneficial for SMX degradation, leading to $65-70 \%$ conversion after $75 \mathrm{~min}$ at either of the three biochar concentrations tested; this said, it appears that the effect of concentration is more pronounced during the early stages of the reaction (i.e., $15 \mathrm{~min}$ ) as conversion takes values of $22 \%, 30 \%$, and $47 \%$ at 100 , 200 , and $300 \mathrm{mg} / \mathrm{L}$ of biochar, respectively.

Figure 10 shows the effect of SPS concentration in the range of $0-1500 \mathrm{mg} / \mathrm{L}$ on SMX degradation with $200 \mathrm{mg} / \mathrm{L}$ biochar.

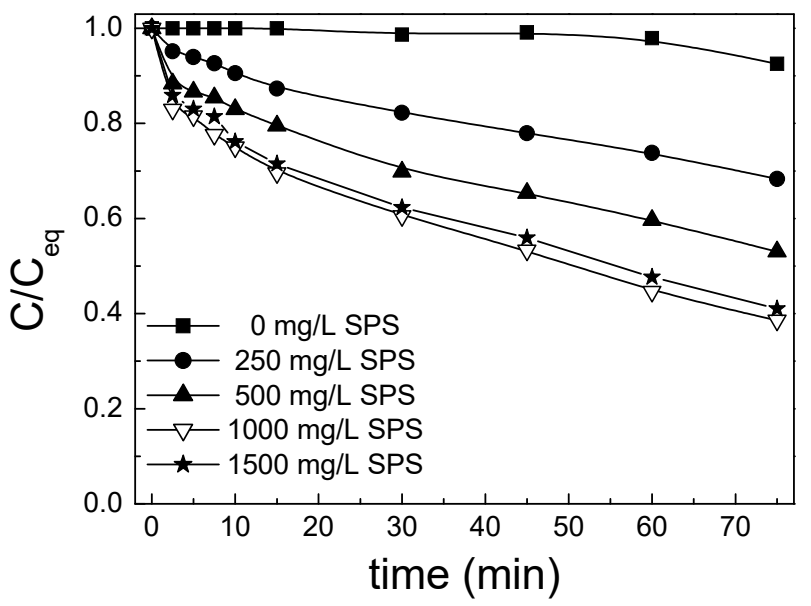

Figure 10. Effect of SPS concentration on $500 \mu \mathrm{g} / \mathrm{L} \mathrm{SMX} \mathrm{degradation} \mathrm{with} 200 \mathrm{mg} / \mathrm{L}$ biochar in UPW and inherent $\mathrm{pH}$.

Adsorption alone is insignificant, but the extent of degradation increases with increasing oxidant concentration up to $1000 \mathrm{mg} / \mathrm{L}$ and remains practically constant thereafter. On the assumption that SMX degradation follows a pseudo-first order kinetic expression, the logarithm of the normalized concentration profiles can be plotted against time to compute the respective apparent rate constants; these are equal to $5.4 \times 10^{-3}, 9.4 \times 10^{-3}, 13.3 \times 10^{-3}$, and $12.2 \times 10^{-3} \mathrm{~min}^{-1}$ for the runs at 250,500 , 1000 , and $1500 \mathrm{mg} / \mathrm{L} \mathrm{SPS}$, respectively. Although increased oxidant concentrations will expectedly generate more radicals, i.e., $\mathrm{SO}_{4} \bullet^{-}$and $\mathrm{OH} \bullet$, this may be counterbalanced by a stronger competitive 
adsorption between SMX and SPS for the biochar's active sites. Furthermore, radicals in excess may suffer partial scavenging and be converted to less reactive species, such as $\mathrm{S}_{2} \mathrm{O}_{8} \bullet^{-}$and $\mathrm{O}_{2}$ [39].

The effect of initial SMX concentration in the range $250-2000 \mu \mathrm{g} / \mathrm{L}$ on its degradation is depicted in Figure 11.

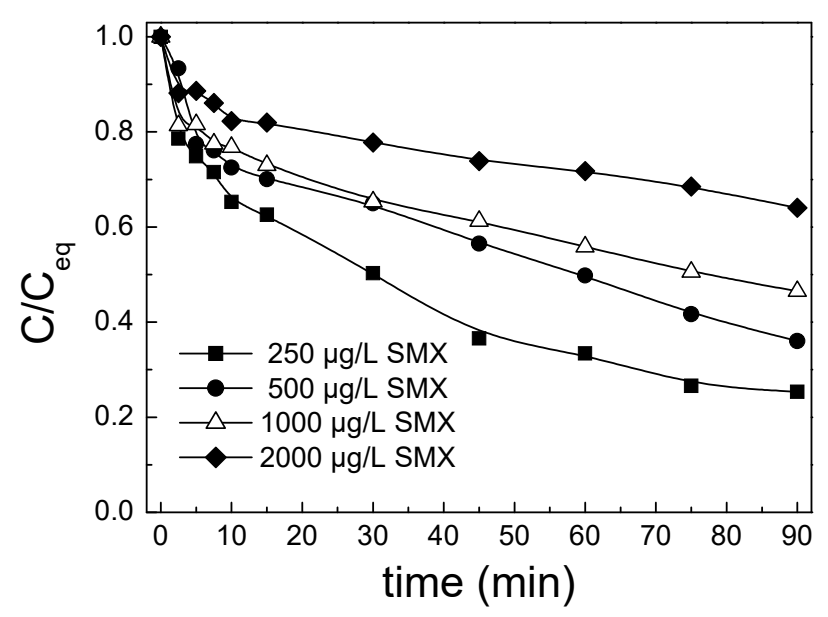

Figure 11. Effect of initial SMX concentration on its degradation with $200 \mathrm{mg} / \mathrm{L}$ biochar and $1000 \mathrm{mg} / \mathrm{L}$ SPS in UPW and inherent $\mathrm{pH}$.

Degradation is clearly retarded at higher substrate concentrations and the apparent rate constants are computed equal to $17.9 \times 10^{-3}, 13.3 \times 10^{-3}, 9.7 \times 10^{-3}$, and $5.6 \times 10^{-3} \mathrm{~min}^{-1}$ for the runs at 250 , 500,1000 , and $2000 \mu \mathrm{g} / \mathrm{L} \mathrm{SMX}$, respectively. These results clearly show that the reaction is not truly first order (although data fitting is still satisfactory) since the rate constant depends on the initial concentration. The fact that the constant decreases with increasing SMX concentration indicates that the reaction shifts towards orders lower than first, reaching eventually the zeroth order. The rationale behind this is associated with the concentration of reactive species relative to the substrate. At a fixed set of operating conditions (i.e., the concentration of biochar and oxidant, $\mathrm{pH}$, water matrix), the concentration of the generated radicals is expected to be nearly constant (this is particularly true at the early stages of the reaction), so the critical factor determining kinetics would be the substrate concentration. As the latter increases, lower rates will occur [30].

\subsubsection{The Water Matrix Effect}

All the experiments described so far were performed in UPW, thus ignoring the possible interactions of the inorganic and organic species typically found in real water matrices. In this respect, additional experiments were performed spiking bottled water (BW) and secondary treated wastewater (WW) with $500 \mu \mathrm{g} / \mathrm{L}$ SMX to study its degradation in the presence of $200 \mathrm{mg} / \mathrm{L}$ biochar and $1000 \mathrm{mg} / \mathrm{L} \mathrm{SPS}$. Interestingly, SMX degradation in BW was as fast as it was in UPW, with the respective rate constants being identical $\left(13.4 \pm 0.1 \times 10^{-3} \mathrm{~min}^{-1}\right)$, but it decreased by about $30 \%$ in WW with a rate constant of $9.3 \times 10^{-3} \mathrm{~min}^{-1}$ (constants were computed from the respective concentration-time profiles, which are not shown for brevity. The same also happens for the experiments with various anions and HA spiked in UPW).

Since bicarbonate is the dominant, in terms of concentration, anion in waters, experiments were performed in UPW adding bicarbonate in the range $50-250 \mathrm{mg} / \mathrm{L}$; the rate constant decreased from $13.3 \times 10^{-3}$ in UPW to $11.8 \times 10^{-3}, 8.9 \times 10^{-3}$, and $8.4 \times 10^{-3} \mathrm{~min}^{-1}$ at 50,100 , and $250 \mathrm{mg} / \mathrm{L}$ bicarbonate, respectively. Similarly, experiments were performed adding chloride or nitrate in UPW; the addition of chloride at 50-250 mg/L slightly retarded the SMX degradation with a rate constant equal to $11.5 \pm 0.3 \times 10^{-3} \mathrm{~min}^{-1}$, while the addition of nitrate at $50-250 \mathrm{mg} / \mathrm{L}$ slightly enhanced degradation with a rate constant equal to $15.1 \pm 1 \times 10^{-3} \mathrm{~min}^{-1}$. These results are in agreement with those in BW 
that contains, amongst others, bicarbonate, chloride, and nitrate anions; although the radicals formed through SPS activation may partly be scavenged by either of these anions, the formation of secondary oxidizing species (e.g., carbonate or chloride radicals) cannot be disregarded, thus compensating for the undesired radical consumption.

An additional experiment was performed adding $10 \mathrm{mg} / \mathrm{L}$ humic acid in UPW to simulate the organic content of the WW sample. The addition of HA had a mild negative effect on SMX degradation with a rate constant equal to $10.9 \times 10^{-3} \mathrm{~min}^{-1}$, in line with the results in WW. Non-target organic species in water may either react with the relatively non-selective radicals or/and compete with the substrate for the surface active sites.

Figure 12a shows temporal SMX profiles normalized against initial (solid lines) and equilibrium (dotted lines) SMX concentrations for UPW and WW. In the case of WW, the two lines practically overlap, implying that SMX adsorption is very low. On the other hand, adsorption partially contributes to SMX removal in UPW, and this contribution is more pronounced during the early stages of the reaction. This implies that non-target matrix components in WW compete with SMX for the active sites. Figure 12b shows the temporal profile of the logarithm of the SMX concentration ratio in UPW and WW. The dependence of the above parameter (the logarithm arises from the fact that the reaction is modeled as pseudo-first order) on time is linear, indicating that the mechanism of degradation is common for the two water matrices. Therefore, the lower degree of degradation in WW can be attributed to the interactions of SPS with non-target matrix components that have competitively been adsorbed on the biochar surface and the subsequent consumption of the generated radicals.
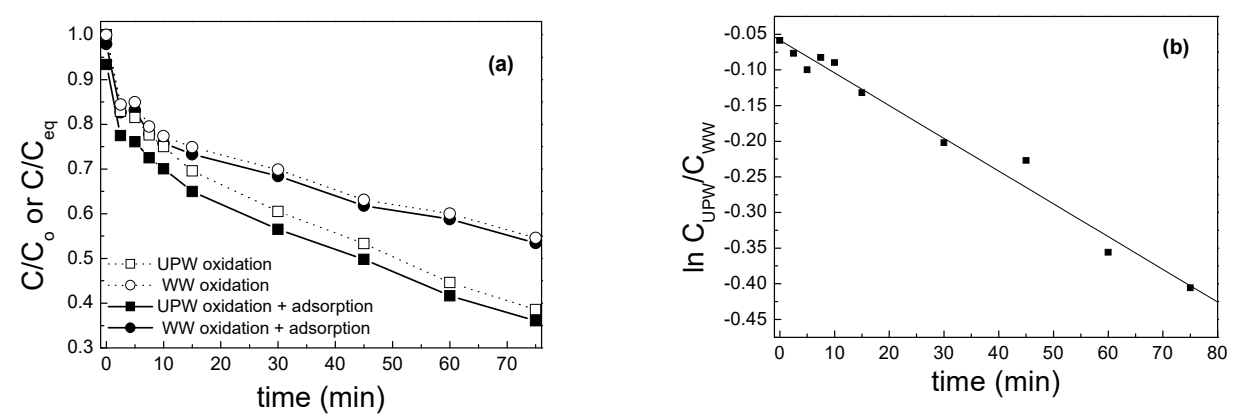

Figure 12. (a) Comparison between the actual oxidation and adsorption process and oxidation alone for SMX removal in UPW and wastewater (WW) with $200 \mathrm{mg} / \mathrm{L}$ biochar and $1000 \mathrm{mg} / \mathrm{L} \mathrm{SPS}$. (b) The linear dependence of the logarithm of SMX concentration ratio in UPW and WW.

\subsubsection{The Role of Radical Scavengers}

In an attempt to evaluate indirectly the role of sulfate and hydroxyl radicals on SMX degradation, experiments were conducted in UPW, adding methanol or $t$-butanol in excess (i.e., 10 and $100 \mathrm{~g} / \mathrm{L}$ ). Both alcohols act as radical scavengers; methanol reacts with both sulfate and hydroxyl radicals at comparable rates, while $t$-butanol reacts preferentially with hydroxyl radicals [40,41]. As seen in Figure 13a, SMX degradation is only partly impeded in the presence of methanol, with the rate constant decreasing by about $25 \%$ and $40 \%$ at 10 and $100 \mathrm{~g} / \mathrm{L}$ alcohol, respectively. The detrimental effect of $t$-butanol (Figure 13b) is more pronounced with the rate constant decreasing by about $45 \%$ at $10 \mathrm{~g} / \mathrm{L}$, while the reaction is completely hindered at $100 \mathrm{~g} / \mathrm{L}$. These findings may imply that (i) hydroxyl radicals dominate over sulfate radicals, and/or (ii) reactions occur not only in the liquid bulk but also in the vicinity of the biochar surface, where adsorption becomes important; this is consistent with the fact that SMX adsorption is not affected in the presence of methanol, but it is completely hindered in the presence of $t$-butanol. 

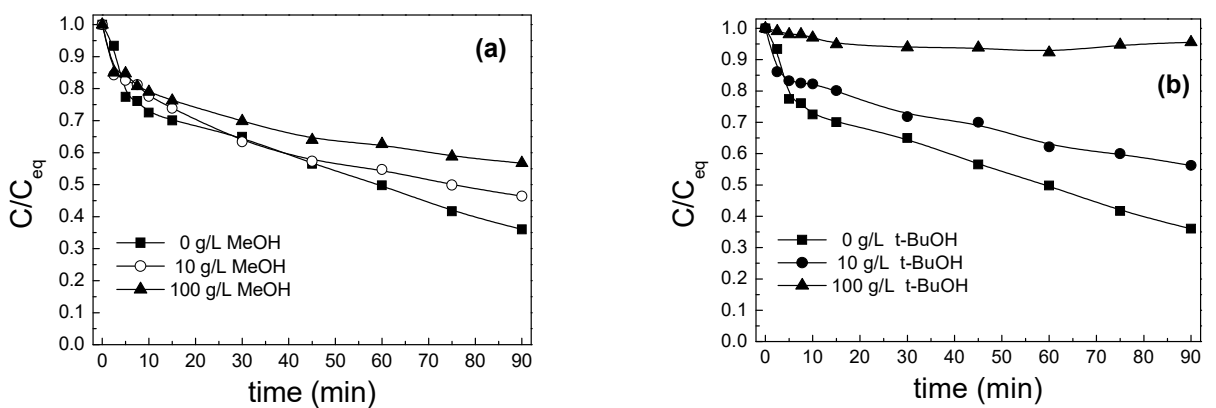

Figure 13. Effect of methanol (a) and $t$-butanol (b) on $500 \mu \mathrm{g} / \mathrm{L} \mathrm{SMX} \mathrm{degradation} \mathrm{with} 200 \mathrm{mg} / \mathrm{L}$ biochar and $1000 \mathrm{mg} / \mathrm{L}$ SPS in UPW and inherent $\mathrm{pH}$.

\section{Materials and Methods}

\subsection{Preparation of Biochar}

The biochar used in this study was prepared from olive stones, the main by-product of the olive-oiland table-olive-producing companies. They were dried overnight at $50^{\circ} \mathrm{C}$ and then heated up to $850^{\circ} \mathrm{C}$ in a limited amount of air. The yield to biochar was $22 \%$ due to the high calcination temperature [27].

\subsection{Chemicals}

Sulfamethoxazole (SMX, $\mathrm{C}_{10} \mathrm{H}_{11} \mathrm{~N}_{3} \mathrm{O}_{3} \mathrm{~S}$, analytical standard, CAS number: 723-46-6) and sodium persulfate (SPS, $\mathrm{Na}_{2} \mathrm{~S}_{2} \mathrm{O}_{8}, 99+\%$, CAS number: 7775-27-1) were purchased from Sigma-Aldrich, St. Louis, MO, USA. Acetonitrile (99.9 wt \%), humic acid (HA, technical grade), sodium hydroxide (98 wt \%), and sulfuric acid (95 wt \%) were also obtained from Sigma Aldrich. Methanol (99.9\%) and t-butanol (99\%) were purchased from Fluka, Loughborough, England.

\subsection{Experimental Procedures}

Experiments were conducted in a cylindrical glass reaction vessel of a $250 \mathrm{~mL}$ capacity that was open to the atmosphere (open air equilibrium). A stock SMX solution was prepared in ultrapure water (UPW), and a measured volume was mixed with the water matrix to achieve the desired SMX concentration (from 250 to $2000 \mu \mathrm{g} / \mathrm{L}$ ). The range of SMX concentrations tested was chosen so that at least $90 \%$ of SMX conversion could be measured. The solution was then supplemented with SPS to achieve the desired concentration of up to $1500 \mathrm{mg} / \mathrm{L}$ biochar to start the reaction under magnetic stirring $(400 \mathrm{rpm})$ and at ambient temperature. Samples of $1.2 \mathrm{~mL}$ were periodically withdrawn from the vessel (every $2.5 \mathrm{~min}$ in the first $10 \mathrm{~min}$ of reaction and every $15 \mathrm{~min}$ from 15 to $120 \mathrm{~min}$ of reaction), filtered and analyzed by liquid chromatography. In most experiments, UPW ( $\mathrm{pH}=6$; $0.056 \mu \mathrm{S} / \mathrm{cm}$ conductivity) was the water matrix, while some experiments were also performed in bottled water (BW, $\mathrm{pH}=7.5 ; 396 \mu \mathrm{S} / \mathrm{cm}$ conductivity; $211 \mathrm{mg} / \mathrm{L}$ bicarbonates; $15 \mathrm{mg} / \mathrm{L}$ sulfates; $9.8 \mathrm{mg} / \mathrm{L}$ chlorides) and secondary treated wastewater (WW, $\mathrm{pH}=8 ; 7 \mathrm{mg} / \mathrm{L}$ total organic carbon; $4.5 \mathrm{mg} / \mathrm{L}$ total suspended solids; $21 \mathrm{mg} / \mathrm{L}$ chemical oxygen demand; $311 \mu \mathrm{S} / \mathrm{cm}$ conductivity; $30 \mathrm{mg} / \mathrm{L}$ sulfates; 0.44 $\mathrm{mg} / \mathrm{L}$ chlorides). Unless otherwise stated, experiments were performed at the matrix's inherent $\mathrm{pH}$; in some experiments, the initial $\mathrm{pH}$ was adjusted or buffered. Most of the experiments were performed in duplicate, and mean values ( $<5 \%$ difference) are quoted as results.

The general kinetic model for a $n$-th order reaction rate is as follows:

$$
\text { Rate }=-\frac{d C}{d t}=k_{a p p} C^{n}
$$


where $C$ is the concentration of SMX, $k_{a p p}$ the apparent rate constant, and $n$ is the reaction order. The value of $k_{\text {app }}$ can be calculated from the slope of the integrated form of Equation (1). For the case of zeroth order reaction $(n=0)$, the integrated form of Equation (1) becomes

$$
C=C_{o}-k_{\text {app }} t
$$

where $C_{o}$ is the initial concentration of SMX. For the case of a first order reaction $(n=1)$, the integrated form of Equation (1) becomes

$$
\ln C=\ln C_{o}-k_{\text {app }} t
$$

\subsection{High Performance Liquid Chromatography (HPLC)}

SMX was analyzed by chromatography using an Alliance HPLC system equipped with a photodiode array detector (Waters 2996 Milford, PA, USA), a gradient pump (Waters 2695, Milford, PA, USA) for solvent delivery $(0.35 \mathrm{~mL} / \mathrm{min})$, and a Kinetex C18 100A column $(150 \times 3 \mathrm{~mm} ; 2.6$ $\mu \mathrm{m}$ particle size) maintained at $45{ }^{\circ} \mathrm{C}$. The isocratic mobile phase consisted of UPW (68\%) and acetonitrile (32\%). The SMX absorbance peaked at $270 \mathrm{~nm}$, as determined from the corresponding UV-vis absorbance spectrum. The limits of SMX detection and quantitation were 6.9 and $20.7 \mu \mathrm{g} / \mathrm{L}$, respectively [42].

\subsection{Physicochemical Characterization}

The biochar was characterized by several techniques as follows: (i) Nitrogen adsorption isotherms were used at liquid $\mathrm{N}_{2}$ temperature (Tristar 3000 porosimeter) for the determination of specific surface area (SSA), micropore surface area, and pore size distribution. (ii) X-ray diffraction (XRD) patterns were recorded in a Bruker D8 (Billerica, MA, USA) Advance diffractometer equipped with a nickel-filtered CuKa (1.5418 $\AA$ ) radiation source. (iii) Surface topography images were obtained using scanning electron microscopy (SEM), EVO MA10 (ZEISS, Oberkochen, Germany), with high vacuum mode in which the chamber vacuum was $1 \times 10^{-5}$ mbar. The samples before SEM measurements were sputtered with an $18 \mathrm{~nm}$ Au thin film in order to avoid electron beam charging phenomena observed in non-conductive samples. For the highest resolution images, the lowest possible beam current used, which was 50 pA. (iv) Fourier transform infrared (FTIR) spectroscopy was performed using a Perkin Elmer Spectrum RX FTIR system. The measurement range was $4000-400 \mathrm{~cm}^{-1}$. (v) Thermogravimetric analysis (TGA) was performed in a TGA Perkin Elmer system (Waltham, MA, USA) under air atmosphere, with a heating rate of $10{ }^{\circ} \mathrm{C} / \mathrm{min}$ in the range $50-900{ }^{\circ} \mathrm{C}$. (vi) To study the acid-base behavior of the biochar, potentiometric mass titration (PMT) was applied [43]. According to PMT, the pzc value of the biochar is the common intersection point of the titration curves of suspensions with different amounts of biochar and the titration curve of a blank solution. The latter contains exactly the same amounts of inert electrolyte and base solution without biochar. Applying the mass balance equation for the $\mathrm{H}^{+}$ions for each titration curve [44], the $\mathrm{H}^{+}$consumption on the biochar surface was determined. More details about the techniques used can be found elsewhere [30].

\section{Conclusions}

In this work, biochars from spent olive stones were synthesized, characterized, and tested for the activation of persulfate to reactive radicals and the subsequent degradation of a model antibiotic micro-pollutant in water matrices. The main conclusions of this study are as follows:

(1) Biochars are characterized by low pzc and mineral content and a moderate specific surface area; the latter is associated with a moderate capacity for SMX adsorption.

(2) Adsorption is strongly affected by solution $\mathrm{pH}$ and is enhanced at acidic environments.

(3) Biochars are capable of activating persulfate, thus inducing SMX oxidative degradation; the single use of either biochar (without oxidant) or oxidants (without biochar) does not practically contribute to SMX removal. 
(4) Degradation rates depend on factors, such as biochar, oxidant, and substrate concentration. An increase in the concentration of the latter retards degradation, while the opposite occurs for the other two factors.

(5) Environmental matrices such as bottled water and wastewater have no or a moderately detrimental effect on degradation; this is encouraging since the process could be applied in real life applications.

(6) It appears that reactions occur both in the liquid bulk and in the vicinity of the biochar surface; this has indirectly been evidenced by the partial inhibition of SMX degradation in the presence of excessive amounts of alcohols in the liquid bulk (i.e., at concentrations 20,000-200,000 times greater than SMX).

(7) Biochars from different biomass sources should be tested for persulfate activation and subsequent organic pollutant degradation to gain a more thorough understanding of the oxidation mechanism and tailor their properties according to specific environmental applications.

Author Contributions: Investigation, E.M., Z.F., J.V., I.D.M. and D.M.; Methodology, E.M., Z.F., J.V., I.D.M. and D.M. All authors have contributed equally.

Funding: J.V. and D.M. acknowledge support of this work by the project "INVALOR: Research Infrastructure for Waste Valorization and Sustainable Management" (MIS 5002495), which is implemented under the Action "Reinforcement of the Research and Innovation Infrastructure", funded by the Operational Programme "Competitiveness, Entrepreneurship and Innovation" (NSRF 2014-2020) and co-financed by Greece and the European Union (European Regional Development Fund).

Acknowledgments: Authors are thankful to Vagelis Karoutsos, University of Patras, Department of Materials Science for SEM measurements.

Conflicts of Interest: The authors declare no conflict of interest.

\section{References}

1. Liu, X.; Zhou, Y.; Zhang, J.; Luo, L.; Yang, Y.; Huang, H.; Peng, H.; Tang, L.; Mu, Y. Insight into electro-Fenton and photo-Fenton for the degradation of antibiotics: Mechanism study and research gaps. Chem. Eng. J. 2018, 347, 379-397. [CrossRef]

2. Ribeiro, A.B.; Dias-Ferreira, C.; Gomes, H.I. Overview of in situ and ex situ remediation technologies for PCB-contaminated soils and sediments and obstacles for full-scale application. Sci. Total Environ. 2013, 445-446, 237-260. [CrossRef]

3. Michael, I.; Frontistis, Z.; Fatta-Kassinos, D. Removal of Pharmaceuticals from Environmentally Relevant Matrices by Advanced Oxidation Processes (AOPs). Compr. Anal. Chem. 2013, 62, 345-407. [CrossRef]

4. Barancheshme, F.; Munir, M. Strategies to Combat Antibiotic Resistance in the Wastewater Treatment Plants. Front. Microbiol. 2018, 8, 2603. [CrossRef] [PubMed]

5. Ioannidou, E.; Frontistis, Z.; Antonopoulou, M.; Venieri, D.; Konstantinou, I.; Kondarides, D.I. Solar photocatalytic degradation of sulfamethoxazole over tungsten-Modified $\mathrm{TiO}_{2}$. Chem. Eng. J. 2017, 318, 143-152. [CrossRef]

6. Dantas, R.F.; Contreras, S.; Sans, C.; Esplugas, S. Sulfamethoxazole abatement by means of ozonation. J. Hazard. Mater. 2008, 150, 790-794. [CrossRef] [PubMed]

7. Ribeiro, R.S.; Frontistis, Z.; Mantzavinos, D.; Venieri, D.; Antonopoulou, M.; Konstantinou, I.; Silva, A.M.T.; Faria, J.L.; Gomes, H.T. Magnetic carbon xerogels for the catalytic wet peroxide oxidation of sulfamethoxazole in environmentally relevant water matrices. Appl. Catal. B Environ. 2016, 199, 170-186. [CrossRef]

8. Hussain, S.; Gul, S.; Steter, J.R.; Miwa, D.W.; Motheo, A.J. Route of electrochemical oxidation of the antibiotic sulfamethoxazole on a mixed oxide anode. Environ. Sci. Pollut. Res. 2015, 22, 15004-15015. [CrossRef]

9. Guo, W.-Q.; Yin, R.-L.; Zhou, X.-J.; Du, J.-S.; Cao, H.-O.; Yang, S.-S.; Ren, N.-Q. Sulfamethoxazole degradation by ultrasound/ozone oxidation process in water: Kinetics, mechanisms, and pathways. Ultrason. Sonochem. 2015, 22, 182-187. [CrossRef]

10. Lutze, H.V.; Bircher, S.; Rapp, I.; Kerlin, N.; Bakkour, R.; Geisler, M.; von Sonntag, C.; Schmidt, T.C. Degradation of Chlorotriazine Pesticides by Sulfate Radicals and the Influence of Organic Matter. Environ. Sci. Technol. 2015, 49, 1673-1680. [CrossRef] 
11. Ioannidi, A.; Frontistis, Z.; Mantzavinos, D. Destruction of propyl paraben by persulfate activated with UV-A light emitting diodes. J. Environ. Chem. Eng. 2018, 6, 2992-2997. [CrossRef]

12. Wang, J.; Wang, S. Activation of persulfate (PS) and peroxymonosulfate (PMS) and application for the degradation of emerging contaminants. Chem. Eng. J. 2018, 334, 1502-1517. [CrossRef]

13. Chenju, L.; Bruell, C.J. Thermally Activated Persulfate Oxidation of Trichloroethylene: Experimental Investigation of Reaction Orders. Ind. Eng. Chem. Res. 2008, 47, 2912-2918. [CrossRef]

14. Anipsitakis, G.P.; Dionysiou, D.D. Radical Generation by the Interaction of Transition Metals with Common Oxidants. Environ. Sci. Technol. 2004, 38, 3705-3712. [CrossRef]

15. Graça, C.A.L.; de Velosa, A.C.; Teixeira, A.C.S.C. Amicarbazone degradation by UVA-activated persulfate in the presence of hydrogen peroxide or $\mathrm{Fe}^{2+}$. Catal. Today 2017, 280, 80-85. [CrossRef]

16. Shao, P.; Tian, J.; Yang, F.; Duan, X.; Gao, S.; Shi, W.; Luo, X.; Cui, F.; Luo, S.; Wang, S. Identification and Regulation of Active Sites on Nanodiamonds: Establishing a Highly Efficient Catalytic System for Oxidation of Organic Contaminants. Adv. Funct. Mater. 2018, 28, 1705295. [CrossRef]

17. Cheng, X.; Guo, H.; Zhang, Y.; Wu, X.; Liu, Y. Non-photochemical production of singlet oxygen via activation of persulfate by carbon nanotubes. Water Res. 2017, 113, 80-88. [CrossRef]

18. Tang, L.; Liu, Y.; Wang, J.; Zeng, G.; Deng, Y.; Dong, H.; Feng, H.; Wang, J.; Peng, B. Enhanced activation process of persulfate by mesoporous carbon for degradation of aqueous organic pollutants: Electron transfer mechanism. Appl. Catal. B Environ. 2018, 231,1-10. [CrossRef]

19. Dimitriadou, S.; Frontistis, Z.; Petala, A.; Bampos, G.; Mantzavinos, D. Carbocatalytic activation of persulfate for the removal of drug diclofenac from aqueous matrices. Catal. Today 2019. [CrossRef]

20. Abbas, T.; Rizwan, M.; Ali, S.; Zia-Ur-Rehman, M.; Farooq Qayyum, M.; Abbas, F.; Hannan, F.; Rinklebe, J.; Ok, Y.S. Effect of biochar on cadmium bioavailability and uptake in wheat (Triticum aestivum L.) grown in a soil with aged contamination. Ecotoxicol. Environ. Saf. 2017, 140, 37-47. [CrossRef]

21. Ahmad, M.; Rajapaksha, A.U.; Lim, J.E.; Zhang, M.; Bolan, N.; Mohan, D.; Vithanage, M.; Lee, S.S.; Ok, Y.S. Biochar as a sorbent for contaminant management in soil and water: A review. Chemosphere 2014, 99, 19-33. [CrossRef]

22. Ali, S.; Rizwan, M.; Noureen, S.; Anwar, S.; Ali, B.; Naveed, M.; Abd_Allah, E.F.; Alqarawi, A.A.; Ahmad, P. Combined use of biochar and zinc oxide nanoparticle foliar spray improved the plant growth and decreased the cadmium accumulation in rice (Oryza sativa L.) plant. Environ. Sci. Pollut. Res. 2019, 26, 11288-11299. [CrossRef]

23. Liu, W.-J.; Jiang, H.; Yu, H.-Q. Development of Biochar-Based Functional Materials: Toward a Sustainable Platform Carbon Material. Chem. Rev. 2015, 115, 12251-12285. [CrossRef]

24. Vakros, J. Biochars and Their Use as Transesterification Catalysts for Biodiesel Production: A Short Review. Catalysts 2018, 8, 562. [CrossRef]

25. Williams, S.; Higashi, C.; Phothisantikul, P.; Van Wesenbeeck, S.; Antal, M.J. The fundamentals of biocarbon formation at elevated pressure: From 1851 to the 21st century. J. Anal. Appl. Pyrolysis 2015, 113, 225-230. [CrossRef]

26. Zhao, L.; Cao, X.; Mašek, O.; Zimmerman, A. Heterogeneity of biochar properties as a function of feedstock sources and production temperatures. J. Hazard. Mater. 2013, 256-257, 1-9. [CrossRef]

27. Manariotis, I.D.; Fotopoulou, K.N.; Karapanagioti, H.K. Preparation and Characterization of Biochar Sorbents Produced from Malt Spent Rootlets. Ind. Eng. Chem. Res. 2015, 54, 9577-9584. [CrossRef]

28. Duan, X.; Sun, H.; Wang, S. Metal-Free Carbocatalysis in Advanced Oxidation Reactions. Acc. Chem. Res. 2018, 51, 678-687. [CrossRef]

29. Huang, B.-C.; Jiang, J.; Huang, G.-X.; Yu, H.-Q. Sludge biochar-based catalysts for improved pollutant degradation by activating peroxymonosulfate. J. Mater. Chem. A 2018, 6, 8978-8985. [CrossRef]

30. Kemmou, L.; Frontistis, Z.; Vakros, J.; Manariotis, I.D.; Mantzavinos, D. Degradation of antibiotic sulfamethoxazole by biochar-activated persulfate: Factors affecting the activation and degradation processes. Catal. Today 2018, 313, 128-133. [CrossRef]

31. Kaczmarczyk, B. FTIR study of conjugation in selected aromatic polyazomethines. J. Mol. Struct. 2013, 1048, 179-184. [CrossRef]

32. Zeng, M.; Shah, S.A.; Huang, D.; Parviz, D.; Yu, Y.H.; Xuezhen Wang, X.; Micah, J.; Green, M.J.; Cheng, Z. Aqueous Exfoliation of Graphite into Graphene Assisted by Sulfonyl Graphene Quantum Dots for Photonic Crystal Applications. ACS Appl. Mater. Interfaces 2017, 9, 30797-30804. [CrossRef] 
33. Luo, J.; Zeng, M.; Peng, B.; Tang, Y.; Zhang, L.; Wang, P.; He, L.; Huang, D.; Wang, L.; Wang, X.; et al. Electrostatic-driven Dynamic Jamming of 2D Nanoparticles at Interfaces for Controlled Molecular Diffusion. Angew. Chem. Int. Ed. 2018, 57, 11752-11757. [CrossRef]

34. Avisar, D.; Primor, O.; Gozlan, I.; Mamane, H. Sorption of Sulfonamides and Tetracyclines to Montmorillonite Clay. Water Air Soil Pollut. 2010, 209, 439-450. [CrossRef]

35. Schott, H.; Astigarrabia, E. Isoelectric Points of Some Sulfonamides: Determination by Microelectrophoresis and by Calculations Involving Acid-Base Strength. J. Pharm. Sci. 1988, 77, 918-920. [CrossRef]

36. Heo, J.; Yoon, Y.; Lee, G.; Kim, Y.; Han, J.; Park, C.M. Enhanced adsorption of bisphenol A and sulfamethoxazole by a novel magnetic $\mathrm{CuZnFe}_{2} \mathrm{O}_{4}$-biochar composite. Bioresour. Technol. 2019, 281, 179-187. [CrossRef]

37. Thiele, $\mathrm{S}$. Adsorption of the antibiotic pharmaceutical compound sulfapyridine by a long-term differently fertilized loess Chernozem. J. Plant Nutr. Soil Sci. 2000, 163, 589-594. [CrossRef]

38. Boxall, A.B.A.; Blackwell, P.; Cavallo, R.; Kay, P.; Tolls, J. The sorption and transport of a sulphonamide antibiotic in soil systems. Toxicol. Lett. 2002, 131, 19-28. [CrossRef]

39. Fang, G.; Wu, W.; Liu, C.; Dionysiou, D.D.; Deng, Y.; Zhou, D. Activation of persulfate with vanadium species for PCBs degradation: A mechanistic study. Appl. Catal. B Environ. 2017, 202, 1-11. [CrossRef]

40. Yin, R.; Guo, W.; Wang, H.; Du, J.; Wu, Q.; Chang, J.-S.; Ren, N. Singlet oxygen-dominated peroxydisulfate activation by sludge-derived biochar for sulfamethoxazole degradation through a nonradical oxidation pathway: Performance and mechanism. Chem. Eng. J. 2019, 357, 589-599. [CrossRef]

41. Yu, J.; Tang, L.; Pang, Y.; Zeng, G.; Wang, J.; Deng, Y.; Liu, Y.; Feng, H.; Chen, S.; Ren, X. Magnetic nitrogen-doped sludge-derived biochar catalysts for persulfate activation: Internal electron transfer mechanism. Chem. Eng. J. 2019, 364, 146-159. [CrossRef]

42. Özkal, C.B.; Frontistis, Z.; Antonopoulou, M.; Konstantinou, I.; Mantzavinos, D.; Meriç, S. Removal of antibiotics in a parallel-plate thin-film-photocatalytic reactor: Process modeling and evolution of transformation by-products and toxicity. J. Environ. Sci. 2017, 60, 114-122. [CrossRef] [PubMed]

43. Bourikas, K.; Vakros, J.; Kordulis, C.; Lycourghiotis, A. Potentiometric Mass Titrations: Experimental and Theoretical Establishment of a New Technique for Determining the Point of Zero Charge (PZC) of Metal (Hydr)Oxides. J. Phys. Chem. B 2003, 107, 9441-9451. [CrossRef]

44. Sfaelou, S.; Vakros, J.; Manariotis, I.D.; Karapanagioti, H.K. The use of Potentiometric Mass Titration technique for determining the acid-base behavior and surface charge of activated sludge. Glob. NEST J. 2015, 17, 397-405. 